\title{
Esophageal Inlet Patch: An Under-Recognized Cause of Symptoms in Children
}

\author{
Giovanni Di Nardo, MD, $\mathrm{PhD}^{1,2}$, Cesare Cremon, $\mathrm{MD}^{3}$, Luca Bertelli, $\mathrm{MD}, \mathrm{PhD}^{3}$, Salvatore Oliva, $\mathrm{MD}^{4}$, \\ Roberto De Giorgio, $\mathrm{MD}, \mathrm{PhD}^{3}$, and Nico Pagano, $\mathrm{MD}^{3}$
}

Objectives To determine the incidence of inlet patch (IP) and to assess the clinical and pathological features, role of the diagnostic workup in treatment decision making, efficacy of medical and endoscopic therapy, and natural history in a pediatric population.

Study design Consecutive patients aged $<18$ years $(n=1000)$ undergoing esophagogastroduodenoscopy were enrolled prospectively. Biopsy specimens were obtained from IPs and the proximal and distal esophagus, stomach, and duodenum. Multichannel intraluminal impedance and $\mathrm{pH}$ monitoring (MII-pH) was performed in all symptomatic patients. Symptomatic patients were treated with proton pump inhibitors for 8 weeks, and IP ablation by argon plasma coagulation (APC) was performed in unresponsive patients.

Results The endoscopic incidence of IP was $6.3 \%$, with a cumulative missing rate of $5.8 \%$. Thirty-five of the 63 patients $(56 \%)$ were asymptomatic, $11(17 \%)$ had symptoms clearly related to the underlying digestive disorder, and $17(27 \%)$ had chronic IP-related symptoms. MII-pH was positive in 10 of the 28 symptomatic patients. All 17 patients with IP-related symptoms were unresponsive to proton pump inhibitors and were treated with APC, and all had achieved complete remission by the 3-year follow-up. Patients with underlying disorders were successfully treated with medical therapy, and asymptomatic patients remained symptom-free, with no endoscopic or histological changes seen at the 3-year follow-up.

Conclusion IP is an under-recognized cause of symptoms in children with unexplained esophageal and respiratory symptoms. MII-pH and bioptic sampling are needed to exclude entities mimicking IP symptoms and to direct therapy. APC is safe and effective for treating IP-related symptoms. (J Pediatr 2016; $\mathbf{\square} \mathbf{\square}-\mathbf{\square})$.

$\mathrm{n}$ inlet patch (IP) is a salmon-colored, velvet-appearing, distinct area of heterotopic gastric mucosa typically located in the proximal esophagus just distal to the upper esophageal sphincter. It is usually a single lesion but can be multiple, ranging in size from a few millimeters to $>5 \mathrm{~cm}$.

The endoscopic-detected incidence of IP ranges from $0.1 \%$ and $10 \%$ in published studies. ${ }^{1,4-6}$ The true incidence may be underestimated; in daily practice, IP is often missed during routine endoscopy. This might be related to the fact that the lower part of the esophagus is more often in the focus of the endoscopist, owing to the frequent pathological findings in this area. ${ }^{5,7,8}$

Although generally asymptomatic, the presence of IP has been associated with laryngopharyngeal symptoms (ie dysphagia, laryngospasms, hoarseness, globus throat discomfort, and chronic cough), likely related to acid production. ${ }^{4,9-13}$ IPs also have been linked to complications including esophageal strictures, tracheoesophageal fistula, ulcerations, bleeding, and perforation. ${ }^{14-18}$ Furthermore, in an autopsy study of a pediatric population, the presence of an IP was associated with unexplained death; the authors speculated that pulmonary aspiration of esophageal contents may cause death in some of these children. ${ }^{19}$

IPs are also potential sites for Helicobacter pylori infection. ${ }^{18,20}$ In addition, Barrett esophagus and adenocarcinoma within IPs have been reported in adults, proving its potential, albeit rare, malignant progression. ${ }^{21-32}$

To date, only a few studies on IP in the pediatric population have been published, most of which are in case report form and limited by their small sample size and retrospective design. ${ }^{10,11,33-38}$ The aims of the present prospective study were to assess: (1) IP in a pediatric population in which the endoscopist is sensitized to search for this entity; (2) the associated clinicopathological

$\begin{array}{ll}\text { APC } & \text { Argon plasma coagulation } \\ \text { AR } & \text { Acid reflux } \\ \text { EGD } & \text { Esophagogastroduodenoscopy } \\ \text { EoE } & \text { Eosinophilic esophagitis } \\ \text { GERD } & \text { Gastroesophageal reflux disease } \\ \text { IP } & \text { Inlet patch } \\ \text { MII-pH } & \text { Multichannel intraluminal impedance and } \mathrm{pH} \text { monitoring } \\ \text { PPI } & \text { Proton pump inhibitor } \\ \text { RSI } & \text { Reflux symptom index } \\ \text { SAP } & \text { Symptom association probability } \\ \text { SI } & \text { Symptom index }\end{array}$


features of IP; (3) the role of the diagnostic workup in treatment decision making; (4) the efficacy of medical and endoscopic therapy; and (5) the natural history of IP.

\section{Methods}

Consecutive patients aged $<18$ years $(\mathrm{n}=1000 ; 621$ females) undergoing esophagogastroduodenoscopy (EGD) for various indications were prospectively assessed for the presence of IP between January 2011 and December 2012 at the Pediatric Gastroenterology Units of the University of Rome and University of Bologna. Patients who underwent endoscopy for such indications as urgent, interventional, capsule placement, enteroscopy, and systemic disorders (eg, Sjögren syndrome, scleroderma) were excluded. The appropriate Institutional Ethical Committees approved the study design. Written informed consent was obtained from all parents, and children when applicable, after they received a thorough explanation of the research protocol.

Before EGD, all patients were carefully questioned about symptoms experienced within the previous month using a self-administered 9-item reflux symptom index (RSI). ${ }^{39} \mathrm{~Pa}$ tients graded the severity of each item from 0 (none) to 5 (severe problem). Clinical response was defined as a reduction in clinical score of at least 3 points for each symptom.

\section{Endoscopic Procedures}

All EGD procedures were performed under general anesthesia by an experienced endoscopist using a video gastroscope (GIF-180; Olympus, Hamburg, Germany). During the procedure, the esophagus was carefully surveyed, with particular attention to the area of the upper esophageal sphincter. This area was best examined by slowly withdrawing the endoscope, with repeated short inflations while rotating the instrument.

IPs were identified as patches covered with salmon-red mucosa distinguishable from surrounding grayish-pearlcolored esophageal mucosa by well-defined margins (Figure 1, A). Each IP was measured by comparing it with the length of the metallic tip of the biopsy forceps $(5 \mathrm{~mm})$.
In patients with multiple patches, the sizes of all patches were summed. Reflux esophagitis and Barrett esophagus were surveyed and classified according to the Los Angeles classification system ${ }^{40}$ and the Praque C \& M criteria, ${ }^{41}$ respectively. Hiatal hernia was considered when the maximum length of the gastric mucosal folds above the gastroesophageal junction exceeded $20 \mathrm{~mm}$.

\section{Histopathological Assessment}

At least 2 biopsy specimens were obtained from each IP using disposable endoscopy biopsy forceps (EndoJaw FB 230V; Olympus). Biopsy specimens were also obtained from the proximal and distal esophagus, fundus, antrum, corpus, and duodenum of the patients with an IP. All biopsy specimens were blindly reviewed by a single pathologist. The squamous mucosa was examined for changes of reflux esophagitis, ${ }^{42}$ and the columnar mucosa was examined for the presence and degree of inflammation and/or intestinal metaplasia according to the modified Sydney classification system. ${ }^{43}$ IP mucosal type was classified based on the presence of parietal and chief cells as antral type, fundic type, or transitional type. The presence of $H$ pylori was evaluated using hematoxylin and eosin and Giemsa staining in the IP and the gastric mucosa.

\section{Multichannel Intraluminal Impedance and pH Monitoring}

The presence of gastroesophageal reflux or IP-related acid production was assessed using multichannel intraluminal impedance and $\mathrm{pH}$ monitoring (MII-pH). For ethical reasons, MII-pH was performed only in symptomatic patients with IP.

The procedure was performed with a combined MII-pH flexible catheter (Covidien-Medtronic, Minneapolis, Minnesota) with 8 impedance rings (representing 6 impedance channels) and 2 antimony $\mathrm{pH}$ sensors. The distal $\mathrm{pH}$ sensor was located at $4.5 \mathrm{~cm}$ from the catheter tip, and the proximal $\mathrm{pH}$ sensor was located $15 \mathrm{~cm}$ from the distal sensor. The 6 impedance channels were located in the MII-pH probe at -2, 0, 2, 4, 13 , and $15 \mathrm{~cm}$ from the distal $\mathrm{pH}$ sensor. The probe was then

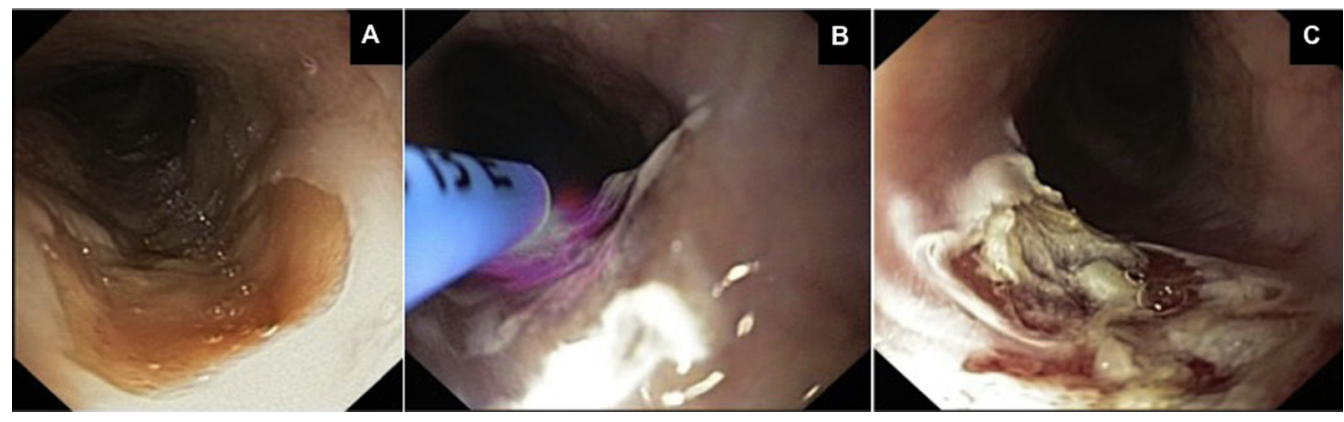

Figure 1. A, Typical endoscopic appearance of IP. B, IP treatment with APC. C, Endoscopic findings at the end of the APC treatment. 
inserted transnasally in the esophagus, and the distal $\mathrm{pH}$ sensor was placed at $87 \%$ of the nares-lower esophageal sphincter distance (Strobel formula) ${ }^{44}$ and verified with fluoroscopy to be at 2 vertebral bodies above the diaphragm. The catheter was connected to a data recorder (Digitrapper $\mathrm{pH}-\mathrm{Z}$; CovidienMedtronic), and data were analyzed with dedicated software (AccuView 5.2; Covidien-Medtronic). Tracings (meal included) were also reviewed manually.

The following MII-pH variables were analyzed: total number of reflux episodes, number of acid reflux (AR) episodes, number of weakly AR and weakly alkaline reflux episodes, percentage of recording time with a $\mathrm{pH}<4$ (RSI), number of proximal reflux episodes, number of episodes of long duration ( $>5$ minutes), number of proximal acidindependent episodes, symptom index (SI), and symptom association probability (SAP). ${ }^{45,46}$

Acid secretion from IP was defined as any recording of $\mathrm{pH}$ $<4$ by the proximal sensor that was not preceded by a recording of $\mathrm{pH}<4$ by the distal sensor. Such episodes are termed "acid-independent" episodes. SI and SAP were calculated for AR, weakly AR, and alkaline reflux and were considered positive at scores of $\geq 50 \%$ and $>95 \%$, respectively. ${ }^{45,46}$

The MII-pH analysis was considered abnormal at an RSI of $>5 \%$ or an SI of $\geq 50 \%$ or SAP of $>95 \%$ for each symptom.

\section{Medical, Endoscopic Therapy, and Follow-up}

Regardless of the MII-pH results, all symptomatic patients were treated with a proton pump inhibitor (PPI) for 8 weeks (omeprazole $2 \mathrm{mg} / \mathrm{kg}$ twice daily, not to exceed $60 \mathrm{mg} /$ day). Ablation of the lesions by argon plasma coagulation (APC) was proposed to patients unresponsive to PPI.

Each APC procedure was performed by 1 of 3 experienced endoscopists using a gastrointestinal argon plasma system (APC 300; ERBE Elektromedizin, Tübingen, Germany) at a power setting of $60 \mathrm{~W}$ and an argon flow of $2 \mathrm{~L} / \mathrm{min}$. A mucosectomy cap was fitted at the distal tip of the endoscope to improve the view and decrease the risk of damage to surrounding squamous epithelium. ${ }^{35,47,48}$ The procedure aimed to completely ablate all IPs in a single session (Figure 1, B and C).

Symptoms were reevaluated at 3 months after APC treatment, with a follow-up endoscopy performed to check for potential side effects (eg, stricture formation) and completeness of ablation. All patients were followed with telephone interviews at $6,12,24$, and 36 months after enrollment. An endoscopic control was proposed to all patients with IP at 3 years after the first endoscopy.

\section{Statistical Analyses}

Demographic characteristics are reported as descriptive statistics: quantitative parameters are expressed as mean $\pm \mathrm{SD}$, and qualitative parameters as absolute and relative frequencies. Symptom incidence was compared between the 2 groups using the Fisher exact test. Comparisons of continuously scaled variables were performed using the parametric independent-samples $t$ test. If assumptions for proper application of the parametric $t$ test (ie, normality and/or homogeneity of variance) were violated, then the nonparametric Mann-Whitney $U$ test was performed. The statistical significance was set at a $P$ value $<.05$ (2-tailed test). All statistical analyses were conducted using SPSS version 19.0 (IBM, Armonk, New York).

\section{Results}

IPs were endoscopically found and biopsy-confirmed in 63 of the 1000 consecutive enrolled children, for an incidence of $6.3 \%$. The study cohort comprised 37 females and 26 males, with a median age of $12 \pm 3.5$ years (range, $4-17$ years). Interestingly, 19 of the IPs were detected in a group of 323 children who underwent previous EGD (performed by another endoscopists than the endoscopist involved in the present study), with a cumulative missing rate of $5.8 \%$. There was no significant difference in the missing rate between the symptomatic patients and the asymptomatic patients $(P=.36)$.

At endoscopy, a single IP was identified in 58 patients, and multiple IPs were detected in 5 patients. The IPs were located just distal to the upper esophageal sphincter and had a median size of $13.3 \pm 6 \mathrm{~mm}$ (range, 5-25 mm). There was no correlation between IP size and presence/absence of symptoms.

Two cases were associated with $H$ pylori erosive gastritis without synchronous colonization of the IP. Three patients had endoscopic findings suggestive of eosinophilic esophagitis (EoE), which was confirmed on histological examination. No patient had erosive esophagitis, Barrett esophagus, or hiatal hernia.

Histology revealed that 26 of the 63 patients had fundic type mucosa in the IP, 17 had antral type mucosa, and 13 had both antral and fundic type mucosa. Five patients had intestinal metaplasia in the IP; 3 of these patients had IP-related symptoms and the other 2 were asymptomatic. Mild to moderate chronic inflammation was seen in 7 patients. There was no correlation between the degree of inflammation and the presence or absence of symptoms. No patients exhibited $H$ pylori infection or any dysplastic changes. EoE was diagnosed in 4 patients, 1 of whom had a normal endoscopic mucosal appearance.

Thirty-five of the 63 patients (56\%) were asymptomatic, and IP was an incidental finding. The clinical indications were celiac disease in 11 patients, ulcerative colitis in 9, Crohn's disease in 13, and Peutz-Jeghers syndrome in 2.

Eleven of the 63 patients (17\%) had symptoms clearly related to the underlying digestive disorder: EoE in 3 patients, $H$ pylori infection in 2, and gastroesophageal reflux disease (GERD) in 6 (in 2 as a consequence of esophageal atresia repair). This was confirmed by complete clinical remission with specific disease-directed therapy.

Seventeen of the 63 patients (27\%) had chronic unexplained symptoms unresponsive to specific therapy, including dysphagia and odynophagia in 2 patients, dysphagia and pyrosis in 3, dysphagia in 2, globus sensation and sore throat in 3, globus sensation and hoarseness in 1, chronic cough in 4 , and laryngospasm in 2 . 
MII-pH was positive in 10 of the 28 symptomatic children. No acid-independent episodes of secretion from the IP were detected.

\section{Clinical Outcomes and Management of Symptomatic Patients}

Among the 17 patients with persistent symptoms, 1 patient with EoE (typical endoscopic and histological finding), dysphagia, and pyrosis had persistent symptoms despite a complete histological remission with oral topical steroid plus PPI therapy negative MII-pH results. Four patients with a MII-pH-based diagnosis of GERD (1 patient with globus sensation and hoarseness, 2 patients with chronic cough, and 1 patient with laryngospasms) had persistent symptoms despite therapy with omeprazole $2 \mathrm{mg} / \mathrm{kg}$ and a second MII-pH performed during the course of PPI therapy showing good acid control with no correlation between symptoms and AR/weakly AR/nonacid reflux events. Twelve symptomatic patients with isolated IP had persistent symptoms despite therapy with omeprazole $2 \mathrm{mg} / \mathrm{kg}$ for 8 weeks.

All 17 patients with persistent symptoms were treated with APC. Endoscopic follow-up performed 3 months after APC showed complete IP eradication in all patients in the absence of complications.

\section{Natural History}

Twelve of the 17 patients treated with APC were asymptomatic at the 3-year clinical follow-up. The patient with EoE required a cycle of standard therapy with satisfactory clinical response and 4 patients with GERD (detected by MII-pH) required PPIs on demand. Endoscopic follow-up after 3 years revealed no residual or recurrent IP lesions in any patients.

The 11 patients with an underlying disorder were treated with standard therapy, and all exhibited a satisfactory clinical response. Endoscopic follow-up performed in all but 2 of the patients at 3 years did not reveal any endoscopic or histological changes. The 2 patients lost to follow-up had H pylori infection and refused repeat endoscopy, and were available only for clinical follow-up (Figure 2; available at www.jpeds.com).

Thirty-five asymptomatic patients continued to be symptom-free at the 3-year follow-up. Endoscopic followup was available for only 25 of these patients. Ten patients with celiac disease refused repeat endoscopy and were available only for clinical follow-up. No endoscopic or histological changes were evident in any of these patients.

\section{Discussion}

Traditionally considered a nonpathological incidental finding, IP has now been identified as the possible cause of unexplained digestive and respiratory symptoms, such as chronic cough, laryngospasm, sore throat, globus pharyngeus, dysphagia, hoarseness, and vocal cord dysfunction, ${ }^{2-7,9-12}$ at least in in a subgroup of patients. Moreover, case reports have shown that IP can play a role in the development of severe complications, such as webs, strictures, ulcers, perforation, fistulas, and adenocarcinoma. ${ }^{14-32}$
The endoscopic incidence of IP in pediatric patients ranges from $0.03 \%$ to $1.4 \%$ in retrospective studies. ${ }^{33,34}$ The sole prospective pediatric study, performed in 407 children, showed a incidence of $5.9 \%,{ }^{11}$ similar to that found in our study population. We found a missing rate of $5.8 \%$ in a selected group of children who had undergone previous EGD. These data confirm results reported by Azar et $\mathrm{al}^{8}$ in adults showing a higher incidence of IP when the operator is aware of the entity. Taken together, these data suggest that IP is a frequently unrecognized entity that has received little attention in the pediatric literature. This may be due to technical difficulties related to endoscopic evaluation of the proximal esophagus. Data from adult studies show that narrow-band imaging increases the detection of IP by approximately 3 -fold compared with standard white light endoscopy. ${ }^{49,50}$

In our series, we did not find associations between IP and erosive esophagitis, Barrett esophagus, or hiatal hernia, but did find an association between IP and EoE. This intriguing finding, although related to the high incidence of EoE in the subjects followed in our center (18 new EoE diagnoses in the study period, and a total of 44 patients with EoE under follow-up), confirms the importance of careful examination and appropriate biopsy sampling of the entire esophagus in children undergoing upper endoscopy for dysphagia.

In our cohort, we found a predominant fundic type mucosa, with no correlation between inflammation degree and symptoms. In contrast to previous reports, ${ }^{18,20,33,34}$ we found no evidence of $H$ pylori colonization. We identified intestinal metaplasia in the IP in 5 patients, 2 of whom were asymptomatic. Given the preneoplastic nature of this abnormality in adults, ${ }^{21,25-32}$ our data support the relevance of IP biopsy sampling to identify patients requiring endoscopic and histological surveillance. Furthermore, future studies based on MII-pH, immunohistochemical, and molecular analyses in all patients (ie, symptomatic and asymptomatic) might explain the development of metaplasia in IP.

An important challenge for clinicians is to determine whether IP is associated with symptoms. Compared with healthy controls, both children and adults with IP have a higher incidence of digestive and respiratory symptoms. ${ }^{1,3-}$ 7,9-12 This led us to hypothesize that acid secretion plays a role in symptom generation and such complications as stricture, ulceration, and fistulas. ${ }^{13,51,52}$ Acid secretion from the IP was documented in only a small proportion of symptomatic patients, however. ${ }^{13,53}$ In this study, we did not find any acid-independent episodes related to IP, suggesting that mechanisms other than acid-induced injury are involved in symptom generation.

Approximately $56 \%$ of our subjects were asymptomatic (ie, IP considered an incidental finding), 17\% had symptoms related to another underlying disorder, and $27 \%$ had IPrelated symptoms. Among the subjects with non-IP-related symptoms, histological analysis and MII-pH monitoring identified 3 cases of EoE, 2 cases of $H$ pylori infection, and 6 cases of GERD, and IP was an incidental finding in all of these subjects. Among the subjects with IP-related symptoms, we identified overlap with EoE in 1 and overlap with GERD in 
4 ; in these patients, complete remission of symptoms was obtained only after IP ablation with APC, suggesting IP as the main cause of the symptoms. In all of the symptomatic cases, an extensive diagnostic workup was essential to correctly identify the role of IP in symptom generation, thereby avoiding unnecessary treatments (eg, surgical treatment for GERD, APC ablation for IP).

There are no standardized treatment strategies for IP. Treatment should be recommended to symptomatic patients and may include pharmacologic therapy with PPIs or $\mathrm{H} 2$ receptor antagonists, complete endoscopic mucosal resection, APC, and dilatation of strictures. ${ }^{1,15-18}$ Only a few previous case reports have suggested the use of PPIs in patients with history of laryngopharyngeal symptoms and IP in this region. Unfortunately, no MII-pH studies were performed in these patients, and for this reason we cannot exclude the possibility of GERD overlap. In our study, 6 of 10 children with IP and pathological MII-pH monitoring suggestive of GERD were successfully treated with PPIs, and in the other 4 children, MII-pH was useful in directing therapy toward IP ablation. A positive effect of APC endoscopic ablation has been demonstrated in adults with IP-related symptoms. ${ }^{48}$ This approach was described in 3 pediatric cases as well, confirming the safety and efficacy of this technique, ${ }^{35}$ although large and long-term follow-up studies are lacking. Here we report the safety and efficacy of APC in 17 patients with IP-related symptoms, who remained asymptomatic at 3-year followup in the absence of endoscopic recurrence.

In conclusion, IP is an under-recognized cause of symptoms and should be suspected during endoscopic examination of children with unexplained esophageal and respiratory symptoms. MII-pH and bioptic sampling of both IP and esophageal mucosa aid in the exclusion of other entities potentially responsible for symptoms and in the choice of appropriate therapeutic management strategies.

Submitted for publication Mar 6, 2016; last revision received Apr 13, 2016; accepted May 18, 2016.

Reprint requests: Giovanni Di Nardo, MD, PhD, Pediatric Gastroenterology Unit, International Hospital Salvator Mundi, Via delle Mura Gianicolensi 67, 00152 Rome, Italy. E-mail: giovanni.dinardo3@alice.it

\section{References}

1. Chong VH. Clinical significance of heterotopic gastric mucosal patch of the proximal esophagus. World J Gastroenterol 2013;19:331-8.

2. Jacobs E, Dehou MF. Heterotopic gastric mucosa in the upper esophagus: a prospective study of 33 cases and review of literature. Endoscopy 1997;29:710-5.

3. von Rahden BH, Stein HJ, Becker K, Liebermann-Meffert D, Siewert JR. Heterotopic gastric mucosa of the esophagus: literature review and proposal of a clinicopathologic classification. Am J Gastroenterol 2004;99: 543-51.

4. Akbayir N, Alkim C, Erdem L, Sökmen HM, Sungun A, Başak T, et al. Heterotopic gastric mucosa in the cervical esophagus (inlet patch): endoscopic prevalence, histological and clinical characteristics. J Gastroenterol Hepatol 2004;19:891-6.

5. Maconi G, Pace F, Vago L, Carsana L, Bargiggia S, Bianchi Porro G. Prevalence and clinical features of heterotopic gastric mucosa in the upper oesophagus (inlet patch). Eur J Gastroenterol Hepatol 2000;12:745-9.
6. Weickert U, Wolf A, Schröder C, Autschbach F, Vollmer H. Frequency, histopathological findings, and clinical significance of cervical heterotopic gastric mucosa (gastric inlet patch): a prospective study in $300 \mathrm{pa}-$ tients. Dis Esophagus 2011;24:63-8.

7. Alaani A, Jassar P, Warfield AT, Gouldesbrough DR, Smith I. Heterotopic gastric mucosa in the cervical oesophagus (inlet patch) and globus pharyngeus: an under-recognised association. J Laryngol Otol 2007;121:885-8.

8. Azar C, Jamali F, Tamim H, Abdul-Baki H, Soweid A. Prevalence of endoscopically identified heterotopic gastric mucosa in the proximal esophagus: endoscopist dependent? J Clin Gastroenterol 2007;41:468-71.

9. Lancaster JL, Gosh S, Sethi R, Tripathi S. Can heterotopic gastric mucosa present as globus pharyngeus? J Laryngol Otol 2006;120:575-8.

10. di Palmo E, Cazzato S, Tursini S, Salfi NC, Mazzotta A, Di Silverio Carulli C, et al. A rare association of inlet patch with laryngospasm: a report of two children and literature review. Pediatr Pulmonol 2011; 46:934-8.

11. Macha S, Reddy S, Rabah R, Thomas R, Tolia V. Inlet patch: heterotopic gastric mucosa-another contributor to supraesophageal symptoms? J Pediatr 2005;147:379-82.

12. Silvers WS, Levine JS, Poole JA, Naar E, Weber RW. Inlet patch of gastric mucosa in upper esophagus causing chronic cough and vocal cord dysfunction. Ann Allergy Asthma Immunol 2006;96:112-5.

13. Korkut E, Bektaș M, Alkan M, Ustün Y, Meco C, Ozden A, et al. Esophageal motility and 24-h $\mathrm{pH}$ profiles of patients with heterotopic gastric mucosa in the cervical esophagus. Eur J Intern Med 2010;21:21-4.

14. Yarborough CS, McLane RC. Stricture related to an inlet patch of the esophagus. Am J Gastroenterol 1993;88:275-6.

15. Rogart JN, Siddiqui UD. Inlet patch presenting with food impaction caused by peptic stricture. Clin Gastroenterol Hepatol 2007;5:e35-6.

16. Kohler B, Köhler G, Riemann JF. Spontaneous esophagotracheal fistula resulting from ulcer in heterotopic gastric mucosa. Gastroenterology 1988;95:828-30.

17. Sánchez-Pernaute A, Hernando F, Díez-Valladares L, González O, Pérez Aguirre E, Furió V, et al. Heterotopic gastric mucosa in the upper esophagus ("inlet patch"): a rare cause of esophageal perforation. Am J Gastroenterol 1999;94:3047-50.

18. Byrne M, Sheehan K, Kay E, Patchett S. Symptomatic ulceration of an acid-producing oesophageal inlet patch colonized by Helicobacter pylori. Endoscopy 2002;34:514.

19. Variend S, Howat AJ. Upper oesophageal gastric heterotopia: a prospective necropsy study in children. J Clin Pathol 1988;41:742-5.

20. Alagozlu H, Simsek Z, Unal S, Cindoruk M, Dumlu S, Dursun A, et al. Is there an association between Helicobacter pylori in the inlet patch and globus sensation? World J Gastroenterol 2010;16:42-7.

21. Neumann WL, Luján GM, Genta RM. Gastric heterotopia in the proximal oesophagus ("inlet patch"): association with adenocarcinomas arising in Barrett mucosa. Dig Liver Dis 2012;44:292-6.

22. Tang P, McKinley MJ, Sporrer M, Kahn E. Inlet patch: prevalence, histologic type, and association with esophagitis, Barrett esophagus, and antritis. Arch Pathol Lab Med 2004;128:444-7.

23. Rosztóczy A, Izbéki F, Németh IB, Dulic S, Vadászi K, Róka R, et al. Detailed esophageal function and morphological analysis shows high prevalence of gastroesophageal reflux disease and Barrett's esophagus in patients with cervical inlet patch. Dis Esophagus 2012;25:498-504.

24. Basseri B, Conklin JL, Mertens RB, Lo SK, Bellack GS, Shaye OA. Heterotopic gastric mucosa (inlet patch) in a patient with laryngopharyngeal reflux (LPR) and laryngeal carcinoma: a case report and review of literature. Dis Esophagus 2009;22:E1-5.

25. Alagozlu H, Ergun M, Cindoruk M, Unal S, Dumlu S, Poyraz A, et al. The rare presentations of a large polyp and an esophageal carcinoma in heterotropic gastric mucosa: a case series. J Med Case Rep 2007;1:127.

26. Abe T, Hosokawa M, Kusumi T, Kusano M, Hokari K, Kagaya H, et al. Adenocarcinoma arising from ectopic gastric mucosa in the cervical esophagus. Am J Clin Oncol 2004;27:644-5.

27. Satoh S, Nakashima T, Watanabe K, Toda S, Kuratomi Y, Sugihara H, et al. Hypopharyngeal squamous cell carcinoma bordering ectopic gastric mucosa "inlet patch" of the cervical esophagus. Auris Nasus Larynx 2007;34:135-9. 
28. Kadota T, Fujii S, Oono Y, Imajoh M, Yano T, Kaneko K. Adenocarcinoma arising from heterotopic gastric mucosa in the cervical esophagus and upper thoracic esophagus: two case reports and literature review. Expert Rev Gastroenterol Hepatol 2016;10:405-14.

29. Probst A, Schaller T, Messmann H. Adenocarcinoma arising from ectopic gastric mucosa in an esophageal inlet patch: treatment by endoscopic submucosal dissection. Endoscopy 2015;47(Suppl 1-UCTN): E337-8.

30. Ajmal S, Young JS, Ng T. Adenocarcinoma arising from cervical esophageal gastric inlet patch. J Thorac Cardiovasc Surg 2015;149:1664-5.

31. Tanaka M, Ushiku T, Ikemura M, Shibahara J, Seto Y, Fukayama M. Esophageal adenocarcinoma arising in cervical inlet patch with synchronous Barrett's esophagus-related dysplasia. Pathol Int 2014;64:397-401.

32. Hudspeth VR, Smith DS, Pacicco T, Lewis JJ. Successful endoscopic resection of adenocarcinoma arising in an esophageal inlet patch. Dis Esophagus 2014; http://dx.doi.org/10.1111/dote.12249 [Epub ahead of print].

33. Georges A, Coopman S, Rebeuh J, Molitor G, Rebouissoux L, Dabadie A, et al. Inlet patch: clinical presentation and outcome in children. J Pediatr Gastroenterol Nutr 2011;52:419-23.

34. Rodriguez-Martinez A, Salazar-Quero JC, Tutau-Gómez C, EspínJaime B, Rubio-Murillo M, Pizarro-Martín A. Heterotopic gastric mucosa of the proximal oesophagus (inlet patch): endoscopic prevalence, histological and clinical characteristics in pediatric patients. Eur J Gastroenterol Hepatol 2014;26:1139-45.

35. Alberty JB, Chanis R, Khoshoo V. Symptomatic gastric inlet patches in children treated with argon plasma coagulation: a case series. J Interv Gastroenterol 2012;2:91-3.

36. Tanpowpong P, Katz AJ. Heterotopic gastric mucosa causing significant esophageal stricture in a 14-year-old child. Dis Esophagus 2011;24:E32-4.

37. Daher P, Francis E, Raffoul L, Riachy E. Ectopic gastric mucosa in the cervical esophagus presenting as a recurrent neck abscess: a case report. J Pediatr Surg 2010;45:e15-7.

38. Karnak I, Senocak ME, Akçören Z, Büykpamukçu N, Hiçsönmez A. Ectopic gastric mucosa causing dysphagia due to strictures in a boy. Eur J Pediatr Surg 1999;9:413-5.

39. Belafsky PC, Postma NG, Koufman JA. Validity and reliability of the reflux symptom index (RSI). J Voice 2002;16:274-7.

40. Armstrong D, Bennett JR, Blum AL, Dent J, De Dombal FT, Galmiche JP, et al. The endoscopic assessment of esophagitis: a progress report on observer agreement. Gastroenterology 1996;111:85-92.
41. Sharma P, Dent J, Armstrong D, Bergman JJ, Gossner L, Hoshihara Y, et al. The development and validation of an endoscopic grading system for Barrett's esophagus: the Prague C\&M criteria. Gastroenterology 2006;131:1392-9.

42. Dahms BB, Rothstein FC. Mucosal biopsy of the esophagus in children. Perspect Pediatr Pathol 1987;11:97-123.

43. Dixon MF, Genta RM, Yardley JH, Correa P. Classification and grading of gastritis: the updated Sydney System. International Workshop on the Histopathology of Gastritis, Houston 1994. Am J Surg Pathol 1996;20: 1161-81.

44. Strobel CT, Byrne WJ, Ament ME, Euler AR. Correlation of esophageal lengths in children with height: application to the Tuttle test without prior esophageal manometry. J Pediatr 1979;94:81-4.

45. Bredenoord AJ, Weusten BL, Smout AJ. Symptom association analysis in ambulatory gastro-oesophageal reflux monitoring. Gut 2005;54:1810-7.

46. Rosen R, Nurko $S$. The importance of multichannel intraluminal impedance in the evaluation of children with persistent respiratory symptoms. Am J Gastroenterol 2004;99:2452-8.

47. Meining A, Bajbouj M, Preeg M, Reichenberger J, Kassem AM, Huber W, et al. Argon plasma ablation of gastric inlet patches in the cervical esophagus may alleviate globus sensation: a pilot trial. Endoscopy 2006;38:566-70.

48. Bajbouj M, Becker V, Eckel F, Miehlke S, Pech O, Prinz C, et al. Argon plasma coagulation of cervical heterotopic gastric mucosa as an alternative treatment for globus sensations. Gastroenterology 2009;137:440-4.

49. Al-Mammari S, Selvarajah U, East JE, Bailey AA, Braden B. Narrow band imaging facilitates detection of inlet patches in the cervical oesophagus. Dig Liver Dis 2014;46:716-9.

50. Chung CS, Lin CK, Liang CC, Hsu WF, Lee TH. Intentional examination of esophagus by narrow-band imaging endoscopy increases detection rate of cervical inlet patch. Dis Esophagus 2015;28:666-72.

51. Nakajima H, Munakata A, Sasaki Y, Yoshida Y. pH profile of esophagus in patients with inlet patch of heterotopic gastric mucosa after tetragastrin stimulation. An endoscopic approach. Dig Dis Sci 1993;38:1915-9.

52. Kim EA, Kang DH, Cho HS, Park DK, Kim YK, Park HC, et al. Acid secretion from a heterotopic gastric mucosa in the upper esophagus demonstrated by dual probe 24-hour ambulatory $\mathrm{pH}$ monitoring. Korean J Intern Med 2001;16:14-7.

53. Hamilton JW, Thune RG, Morrissey JF. Symptomatic ectopic gastric epithelium of the cervical esophagus: demonstration of acid production with Congo red. Dig Dis Sci 1986;31:337-42. 


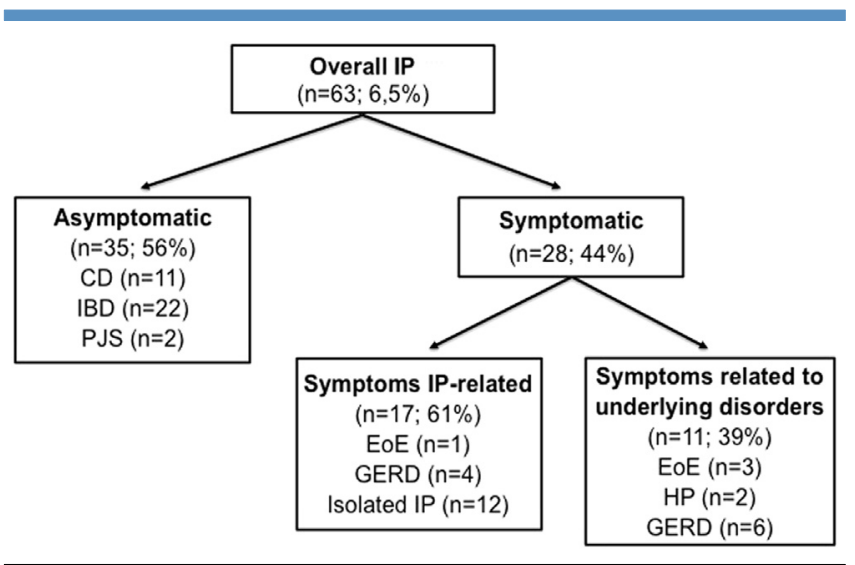

Figure 2. Study flow. IP, inlet patch; $C D$, celiac disease; $I B D$, inflammatory bowel disease; PJS, Peutz-Jeghers syndrome; EoE, eosinophilic esophagitis; GERD, gastroesophageal reflux disease; $H P$, Helicobacter pylori. 